e-journal Keperawatan (e-Kep) volume 7 No. 1 Februari 2019

\title{
HUBUNGAN POLA ASUH ORANG TUA DENGAN PEMBERIAN PENDIDIKAN SEKS PADA ANAK DI KELAS 5 DAN 6 SD INPRES BOYONG PANTE
}

\author{
Moh Akbar P. Djufri \\ Jimmy Posangi \\ WendaOroh
Program Study IlmuKeperawatanFakultasKedokteran
Universitas Sam Ratulangi
Email :bayud49@gmail.com

\begin{abstract}
Sex education is teaching effortsm awareness and provision of information about sexual problems, information provided including knowledge of the functions of reproductive organs by instilling morals, ethics, commitment, and religion, so as not to abuse these reproductive organs. Sex education provided through parenting is expected so that children get the right information about sex, this is due to other media that can teach children about sex. Every parentusually has a different parenting pattern, parenting pattern of perents is divied into three, democratic parenting pattern, permissivea parenting and authoritarian parenting. The purpose of this study was to determine the relationship of parenting parents with the provision of sex education in $5^{\text {th }}$ and $6^{\text {th }}$ graders of SD N Inpres Boyong Pante.The design of this study using Cross Sectional approach, sampling method by total sampling is 41 parents. Instruments in this study from of questionnaires an analyzed using spearman rank statistic with a significance level of 95\%.: $\alpha=0,05$. Spearman rank test results with a significance level of $95 \%(\alpha=0,05)$.Conclusion, three is a relationship of parenting patterns with the provision of sex education in $5^{\text {th }}$ and $6^{\text {th }}$ graders of SD N InpresBoyongPante, where the p.value of both is 0,000 samller than $(\alpha=0,05)$.
\end{abstract}

Keywords: The Parenting Parents, giving sex education to children

\begin{abstract}
Abstrak: Pendidikan seks adalah upaya pengajaran, penyadaran, dan pemberian informasi tentang masalah seksual. Informasi yang diberikan di antaranya adalah pengetahuan tentang fungsi organ reproduksi dengan menanamkan moral, etika, komitmen, dan agama, agar tidak terjadi penyalahgunaan organ reproduksi tersebut. Pendidikan seks yang diberikan melalui pola asuh orang tua diharapkan agar anak mendapat informasi yang tepat mengenaiseks, hal ini dikarenakan adanya media lain yang dapat mengajari anak mengenai pendidikan seks. Pola asuh orang tua berpengaruh terhadap pemberian pendidikan seks pada anak. Setiap orang tua biasanya memiliki pola asuh terhadap anak yang berbeda-beda. Pola asuh orang tua terbagi atas tiga yaitu pola asuh demokratis, pola asuh permisif dan pola asuh otoriter. Tujuan penelitian ini untuk mengetahui hubungan pola asuh dengan pemberian pendidikan seks pada anak kelas 5 dan 6 SD N Inpres Boyong Pante. Metode penelitian ini menggunakan pendekatan cross sectional. Cara pengambilan sampel dengan caratotal sampling yaitu sejumlah 41 orang tua. Instrumen penelitian ini berupa kuesioner dan di analisa menggunakan uji statistic spearman rank dengan tingkat kemaknaan 95\%: $\alpha=0,05$. Hasil uji spearman rank dengan tingkat kemaknaan 95\% $(\alpha=0,05)$, menunjukkan ada hubungan pola asuh dengan pemberian pendidika seks pada anak kelas 5 dan 6 SD N Inpres Boyong Pante, dimana nilai $p$ adalah 0,000 lebih kecil dari $\alpha=0,05$.
\end{abstract}

Kata Kunci: Pola asuh Orang Tua, Pemberian Pendidikan Seks Pada Ana 


\section{PEBDAHULUAN}

Anak merupakan investasi untuk masa depan bangsa sehingga tanggung jawab orang tua dan pendidik harus mengupayakan agar pertumbuhan dan perkembangannya optimal sesuai dengan harapan. Anak harus terus dibina, dibimbing, dan dilindungi agar sehat dan sejahtera baik fisik, emosional, intelektual, social, dan seksualnya. Tanggung jawab orang tua tidak hanya mencakup atau terbatasi pada kebutuhan materi saja, tetapi sesungguhnya mencakup juga kepada seluruh aspek-aspek pendidikan seks (Solihin, 2015).

Pendidikan seks diberikan oleh orang tua dimulai sejak dini, hal ini disebabkan karena mengajarkan seksualitas yang benar membutuhkan proses yang panjang, sejak lahir sampai tahap remaja akhir. Pendidikan seks sejak dini juga harus sesuai dengan perkembangan anak. Pemberian pendidikan seks untuk anak berupa pengetahuan tentang fungsi organ reproduksi serta cara menjaga dan memeliharanya. Seiring bertambahnya usia anak, pendidikan seks juga memberi pengetahuan mengenai cara bergaul yang sehat dan bertanggung jawab sesuai nilainilai ajaran agama dan norma yang berlaku dimasyarakat (Amaliyah, 2017).

Pemahaman pendidikan seks yang diberikan melalui pola asuh orang tua diharapkan agar anak mendapat informasi yang tepat mengenai seks, hal ini dikarenakan adanya media lain yang dapat mengajari anak mengenai pendidikan seks. Pendidikan seks yang diberikan bertujuan agar anak mengetahui mengenai seksualitas dan anak mampu untuk menolak, menghindar, dan mengadu kepada orang terdekat jika ada seseorang yang melakukan tindakan kejahatan seksual. (Jatmikowati, 2015).

Pola asuh orang tua pada anak yaitu berupa interaksi antara anak dan orang tua selama mengadakan kegiatan pengasuhan, mendidik, membimbing, dan mendisiplinkan serta melindungi anak untuk mencapai kedewasaan sesuai dengan norma-norrma yang berlaku di masyarakat. Pola asuh orang tua dibagi menjadi tiga yakni, pola asuh demokratis, otorite, dan permisif (Ilham, 2013).

Pengambilan data awal di kelas 5 dan 6 di SD inpres Boyong pante didapatkan data bahwa jumlah siswa sebanyak 41 anak, terdiri dari 14 siswa laki-laki dan 10 siswa perempuan di kelas 5, dikelas 6 terdapat 8 siswa laki-laki dan 9 siswa perempuan. Wawancara di lakukan pada beberapa anak, didapatkan bahwa rata-rata anak-anak disana tidak pernah mendapatkan pendidikan seks dari orang tua mereka dan sudah pernah menonton film porno di handphone. Orang tua di SD inpres Boyong pante belum pernah memberikan pendidikan seks karena menurut mereka waktunya belum tepat untuk dibeikan pada anak dengan umur yang sekarang ini. Dari hasil tersebut didapatkan 19 orang tua siswa menerapkan pola asuh demokratis, 13 orang tua siswa menerapkan pola asuh ototriter, dan 9 orang tua siswa menerapkan pola asuh pemisif. Hasil tesebut orang tua yang menerapkan pola asuh demokratis didapatkan 17 orang tua yang optimal dalam memberikan pendidikan seks dan 2 orang tua yang kurang optimal dalam memberikan pendidikan seks. Orang tua yang menerapkan pola asuh otoriter didapatkan 5 orang tua yang optimal dalam memberikan pendidikan seks, dan 8 orang tua kurang dalam memberikan pendidikan seks. Orang tua yang menerapkan pola asuh pemisif didapatkan 9 orang tua kurang optimal, dari semua orang tua yang menerapkan pola asuh pemisif tidak ada orang tua yang optimal dalam memberikan pendidikan seks.Berdasarkan masalah yang terjadi serta data yang diperoleh diatas, maka peneliti tertarik melakukan penelitian Hubungan Pola Asuh Orang tua dengan Pemberian Pendidikan Seks pada anak di sd inpres boyong pante. 


\section{METODE PENELITIAN}

Desain penelitian yang dilakukan dalam penelitian ini adalah penelitian kuantitatif. Jenis penelitian yang digunakan adalah deskriptif korelatif dengan menggunakan teknik penelitian cross sectional yaitu untuk mengukur variabel dependen (pemberian pendidikan seks) dan variabel independen (pola asuh orang tua) secara bersamaan. (Setiadi, 2013). Penelitian ini dilaksanakan di SD N Inpres Boyong Pante pada bulan November 2018. Populasi yang digunakan adalah orang tua anak kelas 5-6 yang berjumlah 41 sehingga sampel pada penelitian ini sebanyak 41 orang dengan menggunakan Total Sampling.

Instrument pada penelitian ini menggunakan kuesioner yang terdiri dari dua bagian. Bagian pertama, kuesioner untuk pola asuh orang tua yaitu sebanyak 15 pertanyaan. 5 pertanyaan untuk pola asuh demokratis, 5 pertanyaan untuk pola asuh otoriter, dan 5 pertanyaan untuk pola asuh permisif dengan kriteria skor dan pilihan 1 = tidak pernah, $2=$ kadang-kadang, $3=$ Sering, 4 = Selalu. dengan hasil uji validasi dari pernyataan yang ada, di dapatkan nilai $\mathrm{r}$ tabel $=0.432$ dan dari hasil uji reliabilitas didapatkan nilai alpha $=0.871>0,432$. Bagian kedua, kuesioner untuk pola asuh orang tua yaitu yang terdiri dari 15 pertanyaan. 5 pertanyaan untuk pola asuh demokratis, 5 pertanyaan untuk pola asuh otoriter, dan 5 pertanyaan untuk pola asuh permisif dengan kriteria skor dan pilihan 1 = tidak pernah, 2 = kadang-kadang, $3=$ Sering, $4=$ Selalu. dengan hasil uji validasi dari pernyataan yang ada, di dapatkan nilai $\mathrm{r}$ tabel $=0.432$ dan dari hasil uji reliabilitas didapatkan nilai alpha $=0.871>0,432$.

Analisa Univariat bertujuan untuk menjelaskan atau mendeskripsikan karakteristik setiap variabel penelitian (Notoatmodjo, 2012). Pada penelitian ini, analisis univariat akan menghasilkan distribusi frekuensi yang memberi gambaran mengenai jumlah dan presentase. Analisis univariat dilakukan untuk menganalisa variabel independen dan variabel dependen yaitu pola asuh orang tua dan pemberian pendidikan seks anak usia sekolah.

Analisa bivariat adalah analisis yang dilakukan terhadap dua variabel yang diduga berhubungan atau berkolerasi (Notoatmodjo, 2012). Analisa bivariat merupakan analisa hasil dari variabel independen diduga mempunyai hubungan dengan variabel dependen. Analisa yang digunakan adalah hasil tabulasi silang. Untuk menguji hipotesa dilakukan analisa statistik dengan uji spearman rank pada tingkat kemaknaan 95\% (P.Value < 0,05). Uji korelasi spearman adalah uji statistik yang ditujukan untuk mengetahui hubungan antara dua variable atau lebih. Dengan menginterpretasikan koefisien korelasi sebagai berikut

(r) adalah kekuatan hubungan, $r=0,00$ 0,025 (hubungan lemah), $r=0,26-0,50$ (hubungan sedang), $r=0,51-0,75$ (hubungan kuat), $r=0,76-1,00$ (hubungan sangat kuat).

\section{HASIL dan PEMBAHASAN}

Tabel 1. Distribusi sampel menurut pendidikan orang tua.

\begin{tabular}{ccc}
\hline $\begin{array}{c}\text { Pendidikan } \\
\text { orang tua }\end{array}$ & n & \% \\
\hline $\begin{array}{c}\text { Perguruan } \\
\text { Tinggi }\end{array}$ & 1 & 2,4 \\
SMA & 17 & 41.5 \\
SMP & 12 & 29.3 \\
SD & 11 & 26.8 \\
\hline Total & $\mathbf{4 1}$ & $\mathbf{1 0 0}$ \\
\hline Sumber : Data Primer & 2018 &
\end{tabular}

Hasil penelitian berdasarkan tabel 1 di atas menunjukan bahwa sebagian besar sampel memiliki pendidikan SMA yaitu sebanyak 17 sampel (41,5\%), SMP yaitu sebanyak 12 sampel 29,3\%), SD yaitu sebanyak 11 sampel $(26,8 \%)$, dan sisanya Perguruan tinggi yaitu sebanyak 1sampel $(2,4 \%)$.

Pendidikan orang tua berpengaruh dalam memberikan pendidikan seks pada anak, dimana orang tua yang berpendidikan tinggi akan lebih terbuka menrima informasi. Berbeda halnya orangtua yang mempunyai pendidikan rendah, akan cenderung tidak 
terbuka menerima informasi dari luar, bahkan tidak jarang mereka sering menganggap bahwa pendidikan seks merupakan hal yang tabuh (Noeratih, 2016).

Tabel 2. Distribusi sampel berdasarkan umur orang tua.

\begin{tabular}{ccc}
\hline Umur orang tua & $\mathbf{n}$ & $\mathbf{\%}$ \\
\hline $20-30$ & 17 & 41,5 \\
$31-40$ & 22 & 53,7 \\
$41-50$ & 2 & 4,9 \\
\hline Total & $\mathbf{4 1}$ & $\mathbf{1 0 0} \%$ \\
\hline
\end{tabular}

Sumber : Data Primer, 2018

Hasil penelitian berdasarkan tabel 2 di atas menunjukan bahwa sebagian besar sampel berada pada rentang umur 31-40 tahun yaitu sebanyak 22 sampel $(53,7 \%)$, rentang umur 20 - 30 tahun yaitu sebanyak 17 sampel $(41,5 \%)$, dan sisanya berada pada rentang umur 41-50 tahun yaitu sebanyak 2 sampel $(4,9 \%)$.

Usia merupakan salah satu faktor yang mempengaruhi orang tua untuk dapat menjalankan peran pengasuhan, karena usia yang terlalu muda atau terlalu tua akan menyebabkan peran pengasuhan yang diberikan orang tua menjadi kurang optimal, hal ini disebabkan karena untuk dapat menjalankan peran pengasuhan secara optimal diperlukan kekuatan fisik dan psikososial untuk melakukannya (Supartini 2004).

Tabel 3. Distribusi sampel berdasarkan pola asuh.

\begin{tabular}{lcc}
\hline Pola Asuh & n & \% \\
\hline Demokratis & 19 & 46,3 \\
Otoriter & 13 & 31,7 \\
Pemisif & 9 & 22,0 \\
\hline \multicolumn{1}{c}{ Total } & $\mathbf{4 1}$ & $\mathbf{1 0 0} \%$ \\
\hline
\end{tabular}

Sumber : Data Primer, 2018

Hasil penelitian berdasarkan tabel 3 di atas menunjukan bahwa sebagian besar sampel menerapkan pola asuh demokratis yaitu sebanyak 19 sampel (46,3\%), pola asuh otoriter yaitu sebanyak 13 sampel $(31,7 \%)$, dan sisanya pola asuh permisif yaitu sebanyak 9 sampel (22\%). Pola pengasuhan merupakan suatu proses mendidik, membimbing, dan mendisiplinkan serta melindungi anak untuk mencapai kedewasaan sesuai dengan norma dalam masyarakat, pola asuh dibagi menjadi tiga tipe yaitu otoriter, demokratis, dan permisif (Supartini 2004). Pola asuh demokratis adalah pola asuh yang memprioritaskan kepentingan anak, akan tetapi tidak raguragu mengendalikan mereka. Orang tua dengan pola asuh ini bersikap rasional, selalu mendasari tindakan pada rasio atau pemikiran-pemikiran. Orang tua tipe ini bersikap realistis terhadap kemampuan anak, tidak berharap yang berlebihan yang melampaui kemampuan anak (Djamarah, 2014).

Tabel 4. Distribusi sampel menurut pemberian pendidikan seks.

Sumber : Data Primer, 2018

\begin{tabular}{lcc}
\hline \multicolumn{1}{c}{ Pendidikan seks } & n & \% \\
\hline Optimal & 22 & 53,7 \\
Kurang optimal & 19 & 46,3 \\
\hline \multicolumn{1}{c}{ Total } & $\mathbf{4 1}$ & $\mathbf{1 0 0 \%}$ \\
\hline
\end{tabular}

Hasil penelitian berdasarkan tabel 4 di atas menunujukan bahwa sebagian besaar sampel mendapat pemberian pendidikan seks yang optimal yaitu sebanyak 22 sampel $(53,7 \%)$, dan sisanya kurang optimal yaitu sebanyak 19 sampel (46,3\%).

Pendidikan seks pada anak dapat dimulai dari pengenalan mengenai anatomi tubuh kemudian, meningkat pada pendidikan mengenai cara berkembang biak makhluk hidup, yakni pada manusia dan binatang. Pendidikan seks diawali dengan memperkenalkan bagian tubuh, lambat laun anak akan mengetahui bahwa vagina dan penis berfungsi tidak hanya sebagai jalan untuk buang air kecil, tetapi lebih dari itu, yakni sebagai salah satu alat untuk melakukan reproduksi. Orang tua ataupun pendidik dapat memberitahukan dampak yang akan diterima oleh anak apa 
bila melakukan penyimpangan seksual (Jatmikowati, 2015).

Tabel. 5. Hubungan pola asuh dengan pemberian pendidikan seks pada anak kelas 5 dan 6 SD N Inpres Boyong Pante.

\begin{tabular}{|c|c|c|c|c|c|c|c|}
\hline \multirow{3}{*}{ Pola Asuh } & \multicolumn{4}{|c|}{ PENDIDIKAN SEKS } & \multirow{2}{*}{\multicolumn{2}{|c|}{ Total }} & \multirow{3}{*}{$\mathbf{P}$} \\
\hline & \multicolumn{2}{|c|}{ Optimal } & \multicolumn{2}{|c|}{$\begin{array}{l}\text { Kurang } \\
\text { optimal }\end{array}$} & & & \\
\hline & $\mathbf{n}$ & $\%$ & $\mathbf{n}$ & $\%$ & $\mathbf{n}$ & $\%$ & \\
\hline Demokratis & 17 & 89,4 & 2 & 10,5 & 19 & 100 & \multirow{3}{*}{0,000} \\
\hline Otoriter & 5 & 38,4 & 8 & 61,5 & 13 & 100 & \\
\hline Permisif & 0 & 0 & 9 & 100 & 9 & 100 & \\
\hline Total & 22 & 56,6 & 19 & 46,3 & 41 & 100 & \\
\hline
\end{tabular}

Sumber : Data Primer, 2018

Hasil penelitian berdasarkan tabel $5.5 \mathrm{di}$ atas menunjukan bahwa dari 19 sampel yang mendapatkan pola asuh demokratis didapatkan 17 sampel memiliki pemberian pendidikan seks yang optimal dan 2 sampel yang kurang optimal dalam pemberian pendidikan seks, Kemudian dari 13 sampel yang menerapkan pola asuh otoriter didapatkan 5 sampel yang memiliki pemberian pendidikan seks yang optimal dan sisanya kurang optimal dalam pemberian pendidikan seks yaitu sebanyak 8 sampel, dan yang terakhir dari 9 sampel yang menerapkan pola asuh permisif didapatkan bahwa 9 sampel yang memiliki pemberian pendidikan seks yang kurang optimal. Hasil uji dengan menggunakan uji rank spearman dengan tingkat kepercayaan $95 \% \quad(\alpha 0,05)$, menunjukan adanya hubungan pola asuh orang tua dengan pemberian pendidikan seks pada anak kelas 5 dan 6 SD N Inpres Boyong Pante, dimana nilai $\mathrm{p}=0,000$, lebih kecil dari $(\alpha 0,05)$.

Hasil ini sejalan dengan penelitian yang dilakukan oleh Anggreni (2017) yang mengatakan bahwa ada hubungan antara pola pengasuhan orang tua dengan tindakan kesehatan reproduksi anak dalam rangka pencegahan kekerasan seksual, dimana pola asuh yang paling banyak diterapkan pada anak dalam memberikan pendidikan seks adalah pola asuh demokratis. Hasil penelitian ini didapatkan bahwa dari 19 orang tua yang menerapkan pola asuh demokratis didapatkan 17 responden sudah optimal dalam memberikan pendidikan seks tetapi masih terdapat 2 responden kurang optimal dalam memberikan pendidikan seks. Penelitian yang dilakukan oleh Noeratih (2016). mengatakan bahwa faktor-faktor yang mempengaruhi pola asuh demokratis dalam memberikan pendidikan seks untuk anak yaitu : lingkungan keluarga, pendidikan seks dapat berkembang dengan baik dalam lingkungan keluarga yang sehat dan wajar, yaitu masing-masing anggota keluarga hidup selaras satu sama lain.

Hubungan yang hangat dan terbuka antara orangtua dan anak-anak akan memudahkan komunikasi anatra kedua belah pihak, sehingga kedua belah pihak dapat membicarakan perihal seks dengan perasaan yang wajar dan tidak malu-malu. Faktor lingkungan masyarakat juga mempengaruhi terhadap pendidikan anak, lingkungan masyarakat merupakan bentuk lembaga pendidikan selain keluarga dan sekolah yang akan membentuk kebiasaan, pegetahuan, minat, dan sikap. Kesusilaan kemasyarakatan atau dalam pergaulan diluar keluarga, anak memperoleh pendidikan yang berlangsung secara formal baik dari tokoh masyarakat, pemimpin agama dan lain sebagainya.Adapun faktor yang menghambat orang tua dalam memberikan pendidikan seks pada anak, yaitu kegiatan ekonomi keluarga orangtua yang kurang perhatian pendidikan anaknya, acuh tak acuh terhadap pendidikan yang berkaitan dengan seks, tidak memperhatikan keinginan anaknya maupun lingkungan sekitarnya. Keadaan seperti ini banyak terjadi pada keluarga yang bepenghasilan rendah sehingga mereka kurang memberikan pendidikan seks pada anaknya dan hanya sibuk dengan pekerjaanya (Noeratih, 2016).Pola asuh demokratis merupakan pola asuh yang paling tepat dalam mendidik anak karena anak secara social anak akan menjadi lebih mandiri bertanggung jawab dan lebih pecaya diri, orang tua yang memberikan 
pola asuh ini akan memberikan kepercayaan, perhatian, serta mendorong anak menjadi lebih mandiri.

Pada hasil penelitian 13 reponden yang menerapkan pola asuh otoriter didapatkan 5 responden sudah optimal dalam memberikan pendidikan seks tetapi masih terdapat 8 responden masih kurang optimal. Pada saat penelitian tampak pada orang tua yang menerapkan pola pengasuhan ini terlihat jelas sangat tegas serta disiplin pada sang anak. Pola asuh ini cenderung menetapkan standar yang mutlak harus dituruti, biasanya disertai dengan ancaman-ancaman. Orang tua tipe ini cenderung memaksa, memerintah, menghukum. Apabila anak tidak mau melakukan apa yang dikatakan oleh orang tua, maka orang tua dengan tipe ini tidak segan untuk menghukum anaknya. Orang tua tipe ini juga tidak mengenal kompromi dan dalam komunikasi biasanya bersifat satu arah. Orang tua tipe ini tidak memerlukan umpan balik dari anak untuk mengerti mengenai anak (Djamarah, 2014). Hasil penelitian ini juga didapatkan dari9 responden yang menerapkan pola asuh permisif didapatkan 9 responden tersebut masih kurang optimal dalam memmberikan pendidikan seks. pada saat penelitian orang tua tipe ini selalu menuruti semua perkataan anaknya apapun yang diinginkan anaknya selalu dipenuhi oleh orang tua termasuk keinginan anaknya yang minta disuapi saat makan, orang tua juga tampak sering membela anak dan anak yang mendapat pola pengasuhan ini cenderung terlihat hiperaktif dan jahil. Pola asuh ini memberikan pengawasan yang sangat longgar kepada anak. Memberikan kesempatan pada anak untuk melakukan sesuatu tanpa pengawasan yang cukup. Orang tua cenderung tidak menegur atau memperingatkan anak apabila anak sedang dalam bahaya dan sangat sedikit bimbingan yang diberikan oleh orang tua. Namun orang tua tipe ini bersifat hangat, sehingga seringkali disukai oleh anak (Djamarah, 2014).
Pola pengasuhan orang tua dalam memberikan pendidikan seks kepada anak dipengaruhi oleh beberapa faktor, yaitu : Faktor sosial budaya juga berpengaruh terhadap orangtua dalam mengajarkan pendidikan seks pada anak karena rasa tabu dan malu untuk membicarakan seks pada anak, juga anak usia dini masih dianggap belum pantas dan terlalu kecil untuk mengerjakan pendidikan seks (Alya dan Andika, 2010). Faktor lain yang menyebabkan kurang optimalnya orang tua dalam memberikan pendidikan seks pada anak adalah faktor sosial ekonomi mempengaruhi orangtua dalam mengajarkan pendidikan seks pada anak, semakin lama orangtua bekerja di luar rumah sehingga mengajarkan pendidikan seks menjadi kurang optimal karena orang tua hanya sibuk bekerja. Faktor terakhir yaitu riwayat pendidikan seks, riwayat pendidikan seks mempengaruhi orangtua dalam mengajarkan pendidikan seks pada anak usia dini. Kurangnya pengetahuan yang dimiliki orang tua tentang pendidikan seks, sehingga tidak akan mengajarkan pendidikan seks pada anaknya. (Alya dan Andika, 2010). Faktor pendukung yang kedua tingkat pendidikan keluarga sebagai manusia tentu tidak lepas dari masalah pendidikan, karena manusiahidup dalam lingkungan keluarga dan masyarakat yang syarat dengan pendidikan. dalam hal ini, pendidikan dalam keluarga tingkat pendidikan orang tua sangatmenentukan berhasil dan tidaknya pendidikan anak. Dimana anak yang hidupdalam keluarga berpendidikan cukup tinggi akan mendapatkan perhatian yangkhusus dalam bidang pendidikan seks dibandingkan anakanak yang hidup dalamkeluarga yang berpendidikan rendah. Selain faktor tingkat pendidikan keluarga, komunikasi dengan anak.

Menjalin komunikasi yang terbuka sejak dini dengan anak akan menciptakan jalinan hubunganyang lebih mendalam. Saat hubungan terjalin nyaman,anak akan terbiasa untuk mendiskusikan berbagai haldengan orang tua. Bagi orang tua, hal 
yang perlu diperhatikan bukan hanya tentang materi yang akan disampaikan kepada anak, akan tetapi pertimbangan hubungan yang telah terjalin antara orang tua dan anak juga memiliki peran penting. Jalinan komunikasi yang baik, kepercayaan yang tumbuh antara orang tua dan anak adalah hal yang cukup menunjang agar pendidikan seks dapat tersampaikan dengan baik (Zakiyah, Prabandari, \& Triratnawati, 2016).

Anak tumbuh dan berkembang di bawah asuhan orang tua, melalui orang tua, anak beradaptasi dengan lingkungannya dan mengenal dunia sekitarnya serta pola pergaulan hidup yang berlaku di lingkungannya. Ini disebabkan karena orang tua merupakan dasar pertama bagi pembentukan pribadi anak. Bentuk-bentuk pola asuh orang tua sangat erat hubungannya dengan kepribadian anak setelah ia menjadi dewasa. Orang tua diharapkan dapat menerapkan pola asuh yang bijaksana atau menerapkan pola asuh yang sebaiknya tidak membawa kehancuran atau merusak jiwa dan watak seorang anak (Anggreni \& Notobroto, 2017).

Penyampaian materi pendidikan seksual ini seharusnya diberikan sejak dini ketika anak sudah mulai bertanya tentang perbedaan kelamin antara dirinya dan orang lain, disesuaikan dengan kebutuhan dan umur anak serta daya tangkap anak. Anak usia sekolah (6-12 tahun) merupakan individu yang sedang mengalami masa peralihan yang secara berangsur-angsur mencapai kematangan seksual, mengalami perubahan jiwa dari jiwa kanak-kanak menjadi remaja, dalam hal ini pendidikan seksual idealnya diberikan pertama kali oleh orangtua di rumah melalui pola pengasuhan oleh orang tua, mengingat yang paling tahu keadaan anak adalah orangtuanya sendiri.Hal ini sejalan dengan penelitian dilakukan oleh Paramastri, Supriyati dan Priyanto (2010) mengenai pencegahan dini kekerasan seksual pada anak didapatkan bahwa pola pengasuhan keluarga sangat diperlukan dalam pencegahan kekerasan seksual pada anak.Pencegahan kekerasan seksual pada anak memang harus dimulai sedini mungkin dimulai dari lingkungan keluarga. Pada tahap yang paling awal, keluarga harus memberikan pendidikan seksual bagi anak mengenai perbedaan jenis kelamin laki-laki dan perempuan. Selain pendidikan mengenai jenis kelamin dan perbedaannya, orang tua juga sudah harus membekali anaknya mengenai hal yang boleh dan tidak boleh dilakukan.

\section{SIMPULAN}

Hasil kesimpulan dari pembahasan tentang Hubungan Pola Asuh Orang Tua Dengan Pemberian Pendidikan Seks Pada Anak Kelas 5 dan 6 SD Inores Boyong Pante 2018, bahwa sebagian besar anak di kelas 5 dan 6 SD Inpres Boyong Pante mendapatkan pola asuh demokratis, sebagian besar anak di kelas 5 dan 6 SD Inpres Boyong Pante mendapatkan pemberian pendidikan seks yang optimal, ada hubungan antara pola asuh orang tua dengan pemberian Pendidikan seks dini pada anak kelas 5 dan 6 SD Inpres Boyong Pante.

\section{DAFTAR PUSTAKA}

Anggreni, D., \& Notobroto, B. (2017). Hubungan Pola Pengasuhan Orang Tua Dengan Tindakan Pencegahan Kekerasan Seksual Pada Anak (Studi Kasus Dalam Rangka Pencegahan Kekerasan Seksual Pada Anak Di Kota Mojokerto) Dhonna, 9(1), 9-17.

Andika, Alya. 2010. Ibu, Dari Mana Aku Lahir? Cara Cerdas Mendidik Anak Tentang Seks. Yogyakarta: Pustaka Grhatama

Amaliyah, S. (2017). Pola Pengasuhan Orang Tua dalam Memberikan Pendidikan Seks pada Anank di Desa Jamsari, Poncokusumo, Malang.

Djamarah. (2014). Pola Asuh Orang Tua dan Komunikasi dalam Keluarga. Jakarta: PT Rineka Cipta. 
Ilham, F. (2013). Hubungan Pola Asuh Orang Tua Dengan Pembentukan Kepribadian Remaja Di Smp Handayani Sungguminasa-Gowa. Mycological Research, 106(11), $1323-1330$

Jatmikowati. (2015). a Model and Material of Sex Education for Early-AgedChildren. Cakrawala Pendidikan, No. 03, 434-448.

Notoatmodjo. (2012). Metodologi Penelitian Kesehatan. Jakarta: Rineka Cipta

Noeratih, S. (2016). Peran Orang Tua Terhadap Pendidikan Seks Untuk Anak Usia 4-6 Tahun Di Desa Wanakaya Kecamatan Gunung Jati Kabupaten Cirebon Jawa Barat. Ммит, 2016.

Paramastri, I., Supriyati, \& Priyanto, M. A. (2010). Early Prevention Toward Sexual Abuse on Children. Jurnal Psikologi, 37(1), 1-12. https://doi.org/10.22146/jpsi.7688.

Supartini, Y. (2014). Buku Ajar Konsep Dasar Keperawatan Anak. Jakarta: Penerbit Buku Kedokteran. EGC.

Setiadi. (2013). Konsep dan Praktek Penulisan Riset Keperawatan: Edisi 2. Yogyakarta: Graha Ilmu

Solihin. (2015). Pendidikan Seks untuk Anak Usia Dini: Studi Kasus di TK Bina Anaprasa Melati Jakarta Pusat. Jurnal Pendidikan Sekolah Dasar, (1), 56-74.

Zakiyah, R., Prabandari, Y. S., \& Triratnawati, A. (2016). Tabu, hambatan budaya pendidikan seksualitas dini pada anak di kota Dumai. Berita Kedokteran Masyarakat, 32 no.9. 